\title{
Decolorization of Azo Dyes by PIP Tin Balls in Citric Acid Solution
}

\author{
Shizuo NISHIDE, Mitsuyo HIRAI and Makoto SHODA \\ Chemical Resources Laboratory, Tokyo Institute of Technology, R1-7, 4259, Nagatsuta, \\ Midori-ku, Yokohama, 226-8503, Japan
}

\begin{abstract}
PIP tin balls effectively decolorized azo dyes in citric acid solution and produced $p$-aminobenzene sulfonic acid (ABS) and 1-amino-2-naphthol (1A2N) stoichiometrically by reductive cleavage of Orange II. We performed the decolorization of Orange II under stirring condition to investigate the effect of dissolved oxygen. The decolorization rates estimated using pseudo first-order reactions under anaerobic conditions were significantly higher than those under aerobic conditions. The reductive cleavage of Orange II was inactivated after repeated decolorization reactions in the presence of oxygen. This was associated with the formation of a white precipitate on the surface of the inactivated PIP tin balls, which formed a protective film of oxidized Sn compounds. The surface-area-normalized first-order reaction rate constant $\left(k_{S A}\right)$ for $0.3 \mathrm{mM}$ Orange II, was $0.22\left(1 \mathrm{~m}^{-2} \mathrm{~min}^{-1}\right)$, which was similar to the previously reported value for Orange II decolorization using zero-valent iron powder. Oxidation of metallic tin in the structure of PIP tin balls was considered to be an important factor for the reaction mechanism in the presence of citric acid.
\end{abstract}

Keywords: PIP tin balls; Azo dyes; Decolorization; Citric acid

\section{INTRODUCTION}

The treatment of dye wastewater has attracted attention because of local landscape impacts and also because of potential health effects to living cells. Azo dyes account for $50 \%$ of the total dyes produced worldwide and have potential risk because of toxic aromatic amines produced as reductive metabolic intermediates. Although the physicochemical treatments such as coagulation and flocculation are viable options for the elimination of azo dyes, these produce huge amount of sludge which pose handling and disposal problems. Microbial treatment of azo dyes has been reported in a variety of reaction systems (Mielgo et al., 2001; Stolz, 2001; López et al., 2004). Azo dyes are degraded to aromatic amines under anaerobic conditions, but further degradation of these compounds under anaerobic conditions does not occur. As aromatic amines are decomposed under aerobic conditions, the use of anaerobic-aerobic sequential batch systems has been proposed (Delée et al., 1998; Stolz, 2001; van der Zee and Viellaverde, 2005). However, the decolorization efficiency of azo dyes remains unsatisfactory mainly because of poor decolorization reaction rates. The utilization of heterogeneous zero-valent iron powders for the pretreatment of azo dyes prior to aerobic biological processes is an alternative approach. (Cao et al., 1999; Nam and Tratnyek, 2000; Mu et al., 2004). As a novel heterogeneous process, we proposed the decolorization of azo dyes using immobilized tin components produced by powder impact plating (PIP tin balls). In contrast to iron, there is almost no report with respect to the decolorization of azo dyes using tin. Its potential application in the decolorization of wastewaters from the use of dye was not known. PIP tin ball is commercially available, and has been

Address correspondence to Shizuo Nishide, Chemical Resources Laboratory, Tokyo Institute of Technology, Email: nishide.s.aa@m.titech.ac.jp

Received July 27, 2009, Accepted February 23, 2010. 
utilized to purify the indoor atmosphere. The reaction mechanism is not yet entirely clear. In heterogeneous process, the separation of solid materials after the treatment is an important factor with respect to wastewater treatment. PIP tin ball has comparatively large volume, which is easy to recover. Additionally, vigorous agitation is not needed differently from the type of suspended particle media because of the large effective volumetric capacity, which is costly effective. If the usage of PIP tin balls for decontamination of dye waste is possible, a novel effective treatment could be proposed. It was found that PIP tin balls decolorized four azo dyes which are widely used in textile industries under static condition, which means no stirring at room temperature. We mainly investigated the decolorization characteristics of Orange II as a model azo dye. The decolorization was enhanced in the presence of citric acid. We proposed the decolorization reaction mechanism of azo dyes by PIP tin balls in the presence of citric acid.

\section{MATERIALS AND METHODS}

\section{Chemicals}

The chemical structures of Orange II, Acid yellow 23 and Acid red 27 (Tokyo Kasei Kogyo Co., Ltd., Tokyo, Japan), and Reactive black 5 (Nippon Kayaku Co., Ltd., Tokyo, Japan) are shown in Fig. 1. These reagents were used without further purification. The reagents, $p$-aminobenzene sulfonic acid (ABS), citric acid (Kanto Chemical Co., Ltd., Tokyo, Japan) and 1-amino-2-naphthol (1A2N) (Wako Pure Chemical Industries Co., Ltd., Tokyo, Japan) were of guaranteed reagent grade. The basic structure of PIP tin balls (4 mm diameter; BET surface area $0.0035 \mathrm{~m}^{2} / \mathrm{g}$; average density $3.5876 \mathrm{~g} / \mathrm{cm}^{3}$; Fuji Kihan Co., Ltd., Nagoya, Japan) is shown in Fig. 2. The PIP tin balls consist of an inner carrier of $\mathrm{Al}_{2} \mathrm{O}_{3}$, a tin layer around the carrier and an outer surface of tin oxide ( $\mathrm{SnOx}$, where $\mathrm{x}$ is the stoichiometric ratio of oxygen).
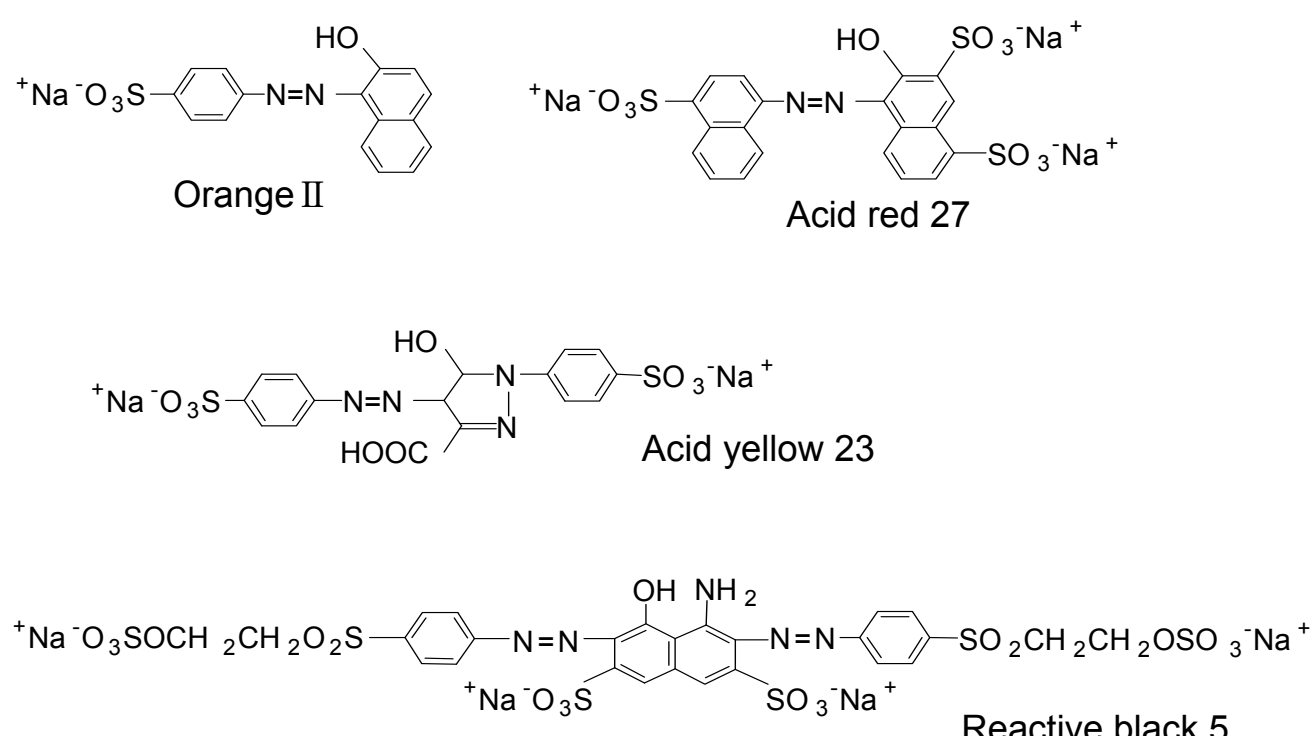

Fig. 1 - Structure of azo compounds used. 


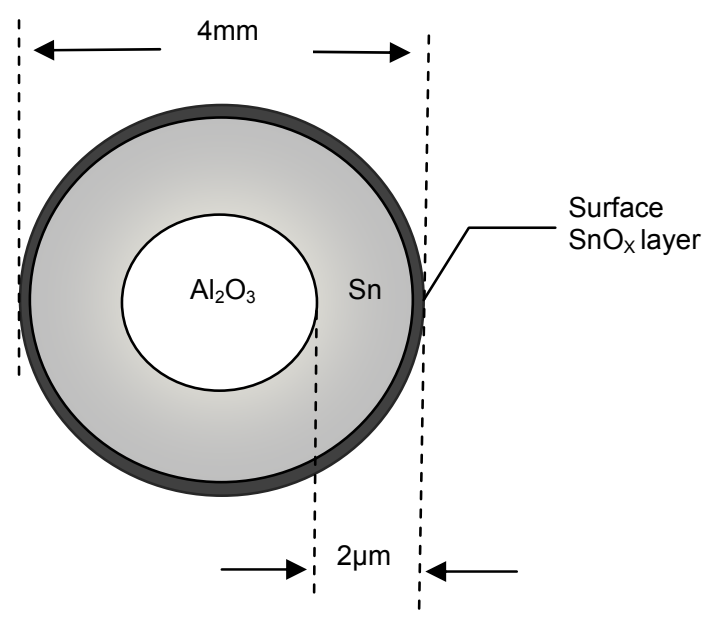

Fig. 2 - Structure of a PIP tin ball. The SnOx layer exhibits the surface tin oxide where the stoichiometric ratio ( $\mathrm{x}$ ) is determined as $0<\mathrm{x}<2$ by XPS analysis.

\section{Decolorization of azo dyes under static conditions}

Decolorization reactions were carried out by the addition of $2.2 \mathrm{ml}$ of different concentrations of azo dyes to Pyrex test tubes $(1 \mathrm{~cm}$ diameter, $10 \mathrm{~cm}$ long) containing 8 $\mathrm{g}$ of PIP tin balls under static conditions at room temperature and atmospheric pressure. The total volume of $8 \mathrm{~g}$ PIP tin balls was about $2.2 \mathrm{~cm}^{3}$. The decolorization was performed at $\mathrm{pH} 3$ in the presence of citrate buffer or hydrochloric acid. The maximum absorbance of each dye (Orange II :485nm, Acid red 27:504nm, Acid yellow 23:426nm, Reactive black 5:595nm) was measured using a UV-Visible spectrophotometer (UV-2200 Shimadzu, Kyoto, Japan), and the absorbance was proportional to the concentration over the tested range. The effect of varying citric acid concentrations $(0-15 \mathrm{mM})$ on the decolorization ratio was also investigated during a 7 -min reaction time under static conditions. In this case, $\mathrm{pH}$ was not controlled. Decolorization ratios were estimated as follows.

$$
\text { Decolorization ratio }(\%)=\left(\mathrm{C}-\mathrm{C}_{\mathrm{PIP}}\right) / \mathrm{C} \times 100
$$

Where $\mathrm{C}$ is the concentration of Orange II in the absence of PIP tin balls after $7 \mathrm{~min}$, and $\mathrm{C}_{\mathrm{PIP}}$ is the concentration of Orange II in the presence of PIP tin balls after $7 \mathrm{~min}$. The initial reaction rates at various initial concentrations of dyes were determined. All experiments were carried out twice, and the average values were used.

\section{HPLC analysis and product identification}

Degradation products of Orange II after static treatment with PIP tin balls in $5 \mathrm{mM}$ citric acid were analyzed by high performance liquid chromatography (HPLC) using filtered reaction solutions through membrane filter (pore size $0.2 \mu \mathrm{m}$; Advantec, Tokyo, Japan). The HPLC was a Jasco PU-980 delivery system equipped with a UV-VIS detector (875UV Jasco, Tokyo, Japan), a column oven (TU-100 Jasco) and a reverse phase C18 column (AG 120, $0.46 \mathrm{~cm} \times 15 \mathrm{~cm}$; Shiseido, Tokyo, Japan). Elution conditions were as follows. The first step was under isocratic conditions with $0.1 \mathrm{M}$ phosphate buffer $(\mathrm{pH}$ 7) for $5 \mathrm{~min}$, the second step used a 10 min linear gradient of water : methanol $(1: 1 \mathrm{v} / \mathrm{v})$ mixture from $0 \%$ to $100 \%$ and the final step employed an isocratic gradient of water : 
methanol $(1: 1 \mathrm{v} / \mathrm{v})$ mixture at a flow rate of $1.0 \mathrm{~mL} / \mathrm{min}$ for $10 \mathrm{~min}$. Eluted materials were detected by their absorbance at $254 \mathrm{~nm}$ and $p$-Aminobenzene sulfonic acid (ABS) was identified by HPLC-mass spectrometry (LC-MS;LC:2690, ESI-MS; ZQ, Waters, Milford, USA). HPLC conditions were the same as described above. 1-Amino-2-naphthol $(1 \mathrm{~A} 2 \mathrm{~N})$ was identified by comparing the retention time of the material with that of an authentic sample, and by co-elution of the test compounds with standard samples. Quantification of products was performed using calibration curves prepared from HPLC of authentic samples.

\section{Decolorization of Orange II under stirred condition}

Reaction solution containing $0.1 \mathrm{mM}$ Orange II and $5 \mathrm{mM}$ citric acid was deoxygenated by bubbling nitrogen gas for $20 \mathrm{~min}$. PIP tin balls $(20 \mathrm{~g})$ were placed in an EVA (ethylene vinyl acetate copolymer) mesh bag which is non-reactive to PIP tin balls and seldom adsorbs dye, and then $300 \mathrm{~mL}$ of the deoxygenized reaction solution was added to the $500 \mathrm{~mL}$ flask which equipped EVA mesh bag entrapping PIP tin balls. Nitrogen gas was bubbled into the solution at room temperature and the mixture was stirred using a magnetic stirrer throughout the reaction. Similar decolorization reactions with continuous stirring were carried out under bubbled air conditions and under ambient conditions. The gas flow rate was $10 \mathrm{~mL} / \mathrm{min}$. One milliliter potion was sampled out periodically. The concentration of Orange II was measured by the spectrophotometer.

\section{Repeated decolorization of Orange II under anaerobic condition}

PIP tin balls $(7 \mathrm{~g})$ were placed in an EVA mesh bag suspended in a $100 \mathrm{~mL}$ round-bottom flask. The flask was sealed with a silicone stopper equipped with a three-way valve, a two-way valve and a sampling tube. Two ports of the three-way valve were connected to a vacuum pump (pump port) and a balloon filled with nitrogen gas (balloon port), respectively. To maintain nitrogen atmosphere in the flask, one port of the two-way valve was connected to a nitrogen cylinder which provided a continuous nitrogen supply. Complete replacement of air in the flask with nitrogen gas was achieved as follows. The balloon port of the three-way valve, the two-way valve and the sampling tube were closed, and the flask was evacuated. The pump port was then closed, and the balloon port was opened to supply nitrogen to the flask. This was repeated three times and then the balloon was removed, and nitrogen gas was supplied continuously. Reaction solution (100 mL of $0.1 \mathrm{mM}$ Orange II in $5 \mathrm{mM}$ citric acid) was deoxygenated by continuous bubbling with nitrogen gas for $20 \mathrm{~min}$ and then added to the flask with a syringe from the balloon port. After $50 \mathrm{~min}, 60 \mathrm{~mL}$ of reacted solution was removed from the flask, $60 \mathrm{~mL}$ of fresh deoxygenated dye solution was added, and decolorization was continued. This procedure was repeated five times. The experiment was also conducted under ambient conditions. In this case, the deoxygenation procedure of reaction solution and continuous nitrogen supply were eliminated, and the two-way valve was opened to expose the reaction solution to air during reaction. At each repeated cycle, initial concentration and the concentration of Orange II after $50 \mathrm{~min}$ was measured by the spectrophotometer. The decolorization ratio at $50 \mathrm{~min}$ was compared at each cycle. The decolorization ratio was estimated as follows.

$$
\text { Decolorization ratio }(\%)=\left(\mathrm{C}_{\mathrm{o}}-\mathrm{C}_{50 \mathrm{~min}}\right) / \mathrm{C}_{\mathrm{o}} \times 100
$$


Where $\mathrm{C}_{\mathrm{o}}$ is the initial concentration and $\mathrm{C}_{50 \mathrm{~min}}$ is the concentration of Orange II after 50 min.

\section{FT-IR measurement}

Fourier transform infrared spectrometry (FT-IR) was used to analyze the white precipitate which appeared on inactivated PIP tin balls during the experiment under ambient conditions. The surface of the balls was shaven by a blade to remove the precipitate. A disk including the precipitate was prepared by pressing the shavings with $\mathrm{KBr}$ powder and was used for FT-IR (660-plus; Jasco). Crystalline citric acid was used as reference.

\section{XPS measurement}

X-ray photoelectron spectroscopy (XPS) spectra of fresh and inactivated PIP tin balls were obtained at Shimadzu Co., Ltd. Laboratory. The non-mono-chromatized Al-K $\alpha$ radiation source was applied to two PIP tin balls at $15 \mathrm{kV}$ and $10 \mathrm{~mA}$. The measurement was performed with a take-off angle close to $90^{\circ}$.

\section{RESULTS AND DISCUSSION}

\section{Decolorization of azo dyes by PIP tin balls under static conditions}

\section{The effect of citric acid}

Table 1 shows the decolorization ratios for four azo dyes (all at $0.3 \mathrm{mM}$ ) after 7-min reaction time under static conditions using PIP tin balls in citrate buffer $(5 \mathrm{mM}, \mathrm{pH} 3)$ or in hydrochloric acid at $\mathrm{pH} 3$. Decolorization ratios in the presence of citrate were greater than those in hydrochloric acid, except for Reactive black 5.

Table 1 - Decolorization ratios for four dyes by PIP tin balls in 7 min under static conditions. (The pH was adjusted to 3 using citric acid or hydrochloric acid. PIP tin ball : $8 \mathrm{~g}$; initial concentration of dyes : $0.3 \mathrm{mM}$; reaction solution volume: $2.2 \mathrm{~mL}$ )

\begin{tabular}{lcccc}
\hline & \multicolumn{4}{c}{ Decolorization ratio [\%] } \\
\cline { 2 - 5 } & Acid yellow 23 & Acid red 27 & Reactive black 5 & Orange II \\
\hline With citrate & 33 & 43 & 10 & 64 \\
With hydrochloric acid & 1 & 7 & 22 & 33 \\
\hline
\end{tabular}

Fig. 3 shows the decolorization ratios of Orange II by PIP tin balls with a reaction time of 7 min under static conditions and solution $\mathrm{pH}$ at various citric acid concentrations. The decolorization reaction did not occur without PIP tin balls. The decolorization ratio increased to $70 \%$ in a concentration-dependent manner with increasing citric acid concentration up to $10 \mathrm{mM}$, but no increase in the decolorization ratio was observed above this concentration. 


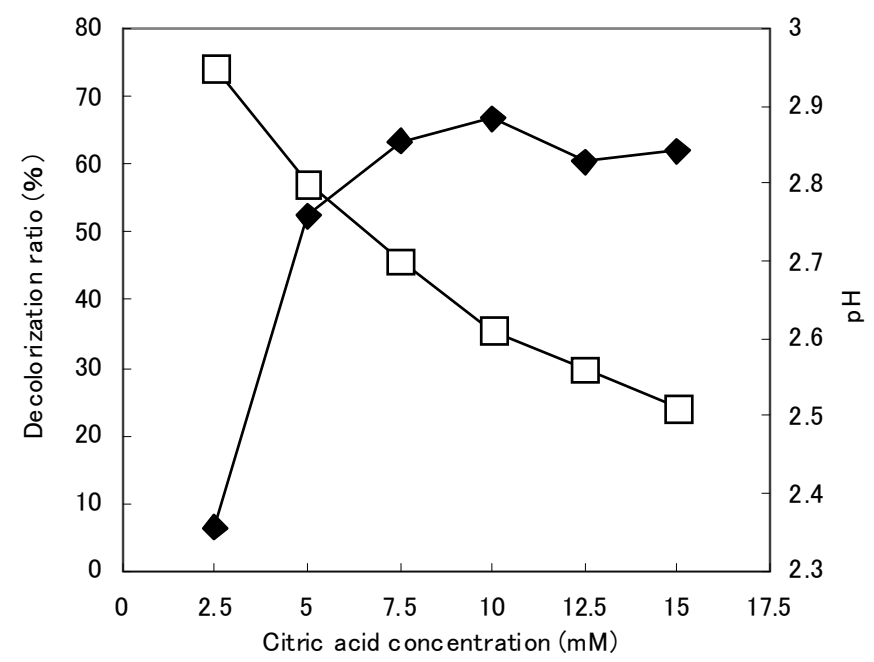

Fig. 3 - Decolorization ratios of Orange II by PIP tin ball in $7 \mathrm{~min}$ under static condition and $\mathrm{pH}$ at various citric acid concentrations. $\diamond$ : Decolorization ratio; $\square: \mathrm{pH}$; PIP tin ball : $8 \mathrm{~g}$; initial concentration of Orange II : $0.3 \mathrm{mM}$; reaction solution volume : $2.2 \mathrm{~mL}$

\section{Products after decolorization of Orange II}

HPLC chromatogram of the products of Orange II degradation after 10 min under static conditions in $5 \mathrm{mM}$ citric acid with PIP tin balls showed three major peaks. Orange II was detected at a retention time of $30.1 \mathrm{~min}$. Two new peaks appeared with retention times of 2.1 and 20.6 min (data not shown). Fig. 4 shows the negative ion MS spectrum of the component with a retention time of $2.1 \mathrm{~min}$.

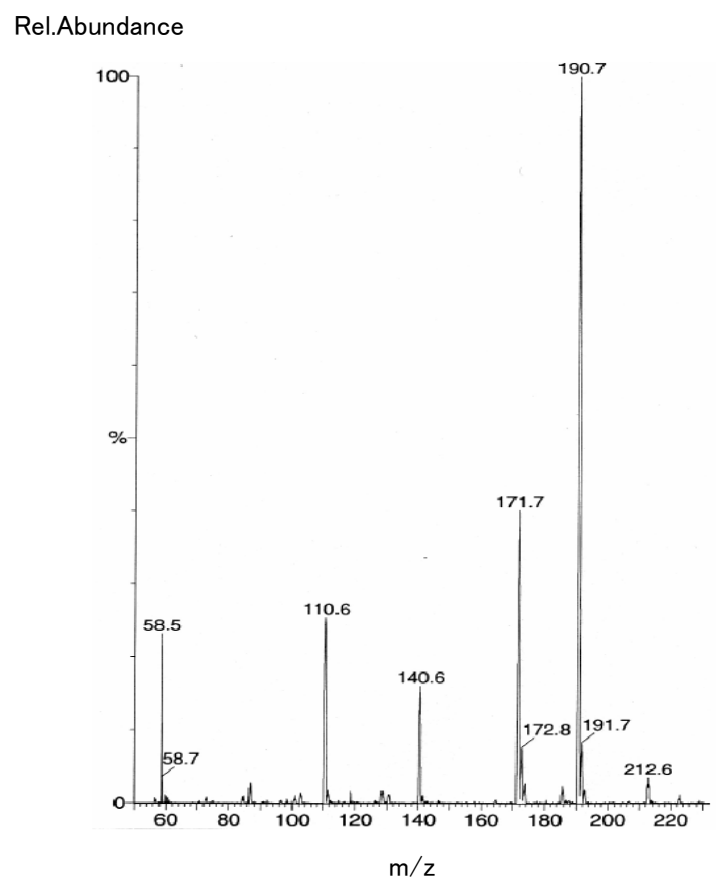

Fig. 4 - LC-MS-spectrum of the peak at retention time of $2.1 \mathrm{~min}$ in HPLC analysis.

The ion peak (M-H-) at 190.7 is indicative of citric acid (molecular weight 191). An ion peak at (M-H-) 171.7 was confirmed to be $p$-aminobenzene sulfonic acid (ABS) 
(molecular weight 173) by correlating the HPLC retention time with that of an authentic sample. The component with the retention time of $20.6 \mathrm{~min}$ was identified as 1-amino-2-naphthol $(1 \mathrm{~A} 2 \mathrm{~N})$ by comparing the retention time of the sample with that of an authentic sample and by co-elution using HPLC (data not shown). HPLC and LC-MS results indicated that Orange II was reductively cleaved by PIP tin balls to two hydrogenated products, ABS and $1 \mathrm{~A} 2 \mathrm{~N}$ as follows.

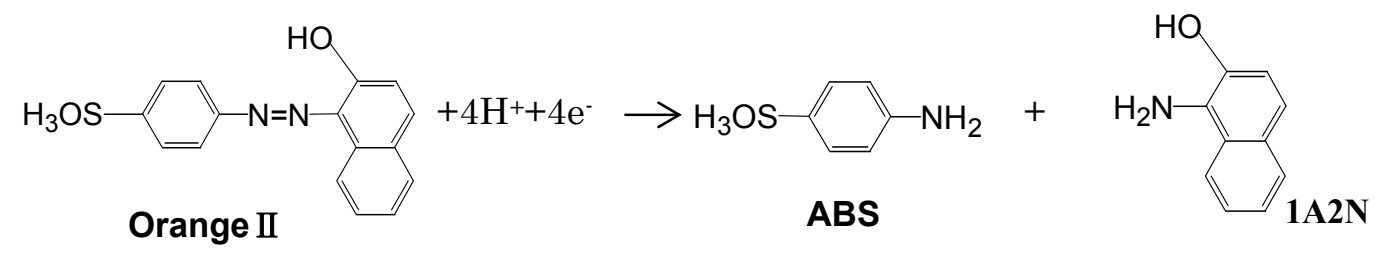

Time-course concentrations of Orange II and the two degradation products during reaction with PIP tin balls are shown in Fig. 5. Rapid analysis after sampling of reaction solution and the acidic solution could prevent the effect of auto-oxidation of $1 \mathrm{~A} 2 \mathrm{~N}$ on the quantification. Orange II was not detected after $20 \mathrm{~min}$, at which time stoichiometrically equivalent amounts of $\mathrm{ABS}$ and $1 \mathrm{~A} 2 \mathrm{~N}$ accumulated, and their concentrations showed no further change after $30 \mathrm{~min}$. This shows that the degradation of Orange II by PIP tin balls was irreversible, and that further decomposition of the two products did not occur.

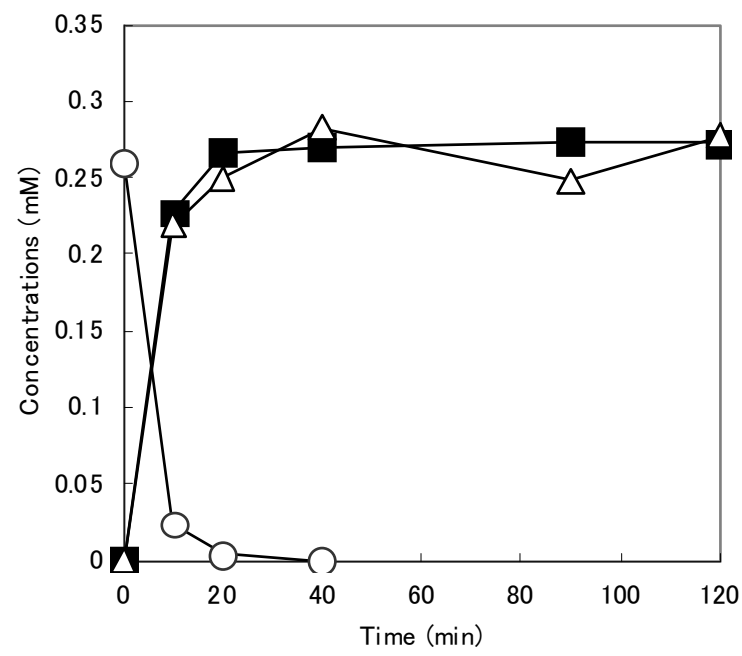

Fig. 5 - Time course of Orange II degradation products by PIP tin ball under static condition. PIP tin ball : $8 \mathrm{~g}$; reaction solution volume : $2.2 \mathrm{~mL} ; \bigcirc$ :Orange II; $\mathbf{\square}: \mathrm{ABS} ; \triangle: 1 \mathrm{~A} 2 \mathrm{~N}$.

\section{Decolorization of Orange II under stirred condition}

\section{The effect of oxygen}

The time course of Orange II degradation by PIP tin balls without gas supply (ambient), with air bubbling and with nitrogen bubbling was investigated. A plot of $\ln \left(\mathrm{C}_{\mathrm{o}} / \mathrm{C}\right)$ versus time showed a linear relationship (Fig. 6), indicating the kinetics fit pseudo first-order model. The reaction rate constant obtained with nitrogen bubbling was $5.1 \times 10^{-2} \mathrm{~min}^{-1}$, which was greater than with air bubbling $\left(2.4 \times 10^{-2} \mathrm{~min}^{-1}\right)$ or without gas supply $\left(2.9 \times 10^{-2} \mathrm{~min}^{-1}\right)$. Under nitrogen bubbling conditions, the surface-area-normalized first order rate constant $\left(k_{S A}\right)$ was estimated to be $0.215\left(\mathrm{~L} \mathrm{~m}^{-2}\right.$ $\left.\min ^{-1}\right)$, which is almost the same as the reported $k_{S A}=0.21\left(\mathrm{~L} \mathrm{~m}^{-2} \mathrm{~min}^{-1}\right)$, for 
decolorization of $0.3 \mathrm{mM}$ Orange II with zero-valent iron (Nam and Tratnyek, 2000).

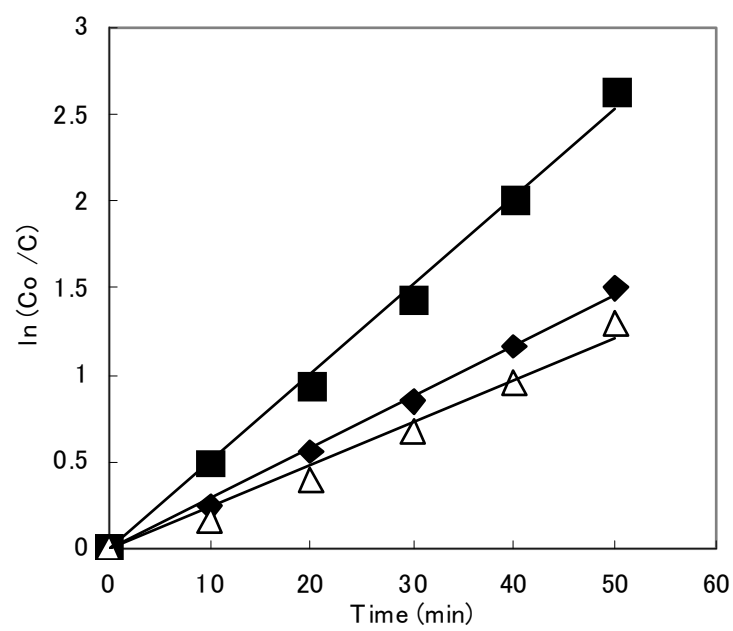

Fig. 6 - Plot of $\ln (\mathrm{Co} / \mathrm{C})$ versus $t$ during the decolorization of Orange II (Co is the initial concentration and $\mathrm{C}$ is the concentration at time ' $\mathrm{t}$ '). Air bubbling condition $(\triangle)$, no gas supply condition ( and $\mathrm{N}_{2}$ bubbling condition ( $\left.\mathbf{\square}\right)$.

\section{Repeated decolorization of Orange II}

Decolorization in repeated 50-min reactions was performed under anaerobic conditions established by continuous bubbling with nitrogen. A control experiment was conducted under ambient conditions. The initial concentration of Orange II and the decolorization ratios obtained during five reaction cycles are shown in Table 2. Considering subsequent biological treatment, complete decomposition of Orange II is needed. It is reported that Orange II inhibits microbial metabolism (Albuqueruue et al., 2005). Almost complete decolorization was obtained by 50 -min reaction in both cases. This result showed a possibility of PIP tin balls for the pretreatment of azo dye. A decrease in the decolorization ratios under ambient conditions was evident, but only a slight decrease in decolorization ratios was observed under anaerobic conditions. A white precipitate progressively covered the surface of the tin balls during repeated decolorization under ambient conditions. Once the white precipitate was removed, the ball regained decolorization activity (data not shown). This indicates that the precipitate on the surface of the balls was related with the inactivation of the balls.

Table 2 - Initial concentrations of Orange II and decolorization ratios obtained in repeated 50-min reaction cycles.

\begin{tabular}{ccccc}
\hline $\begin{array}{c}\text { Repeated } \\
\text { cycles }\end{array}$ & \multicolumn{2}{c}{ Anaerobic condition } & \multicolumn{2}{c}{ Ambient condition } \\
Initial conc. & {$[\mathrm{mM}]$} & $\begin{array}{c}\text { Decolorization } \\
\text { ratio }[\%]\end{array}$ & $\begin{array}{c}\text { Initial conc. } \\
{[\mathrm{mM}]}\end{array}$ & $\begin{array}{c}\text { Decolorization } \\
\text { ratio } \\
{[\%]}\end{array}$ \\
\hline 1 & $9.6 \times 10^{-2}$ & 99 & $9.6 \times 10^{-2}$ & 96 \\
2 & $5.0 \times 10^{-2}$ & 99 & $4.9 \times 10^{-2}$ & 93 \\
3 & $5.8 \times 10^{-2}$ & 99 & $5.0 \times 10^{-2}$ & 85 \\
4 & $6.0 \times 10^{-2}$ & 96 & $5.1 \times 10^{-2}$ & 63 \\
5 & $6.0 \times 10^{-2}$ & 96 & $5.5 \times 10^{-2}$ & 56 \\
\hline
\end{tabular}


Unused PIP tin balls and the PIP tin balls which were inactivated by repeated use under ambient condition were analyzed by XPS. Sn3d spectra of unused PIP tin balls and an inactivated ball are shown in Fig. 7. The small bands at $485 \mathrm{eV}$ (b in the figure) and 493 $\mathrm{eV}$ ( $\mathrm{a}$ in the figure) in the spectrum of unused PIP tin balls were assigned to metallic tin and were not found in spectrum of inactivated PIP tin balls. According to Willemen et al. (1979), the central positions of the $\mathrm{Sn} 3 \mathrm{~d}_{5 / 2}$ spectrum peaks in $\mathrm{Sn}$ (II) and $\mathrm{Sn}$ (IV) oxide compounds are $486.3 \pm 0.6 \mathrm{eV}(\mathrm{SnO})$ and $486.9 \pm 0.6 \mathrm{eV}\left(\mathrm{SnO}_{2}\right)$, respectively. This means that it is not possible to distinguish $\mathrm{Sn}$ (II) and $\mathrm{Sn}$ (IV) from the binding energy data. The central position of the $S n 3 d_{5 / 2}$ of the inactivated one was slightly higher compared with that of the fresh one. This indicated that the tin of higher oxidation state is occupied in inactivated PIP tin balls. Atomic concentrations of $\mathrm{C}, \mathrm{O}$, and $\mathrm{Sn}$ were investigated in fresh and inactivated PIP tin balls from XPS. Atomic ratios to total $\mathrm{Sn}$ are shown in Table 3. The increase in the atomic ratios of $\mathrm{C} / \mathrm{Sn}$ and $\mathrm{O} / \mathrm{Sn}$ was observed in inactivated PIP tin balls. This indicates that the precipitates covering the surface of inactivated PIP tin balls are $\mathrm{Sn}(\mathrm{IV})$ species such as $\mathrm{SnO}_{2}$ and/or $\mathrm{Sn}(\mathrm{OH})_{4}$ along with incorporating carbon species.

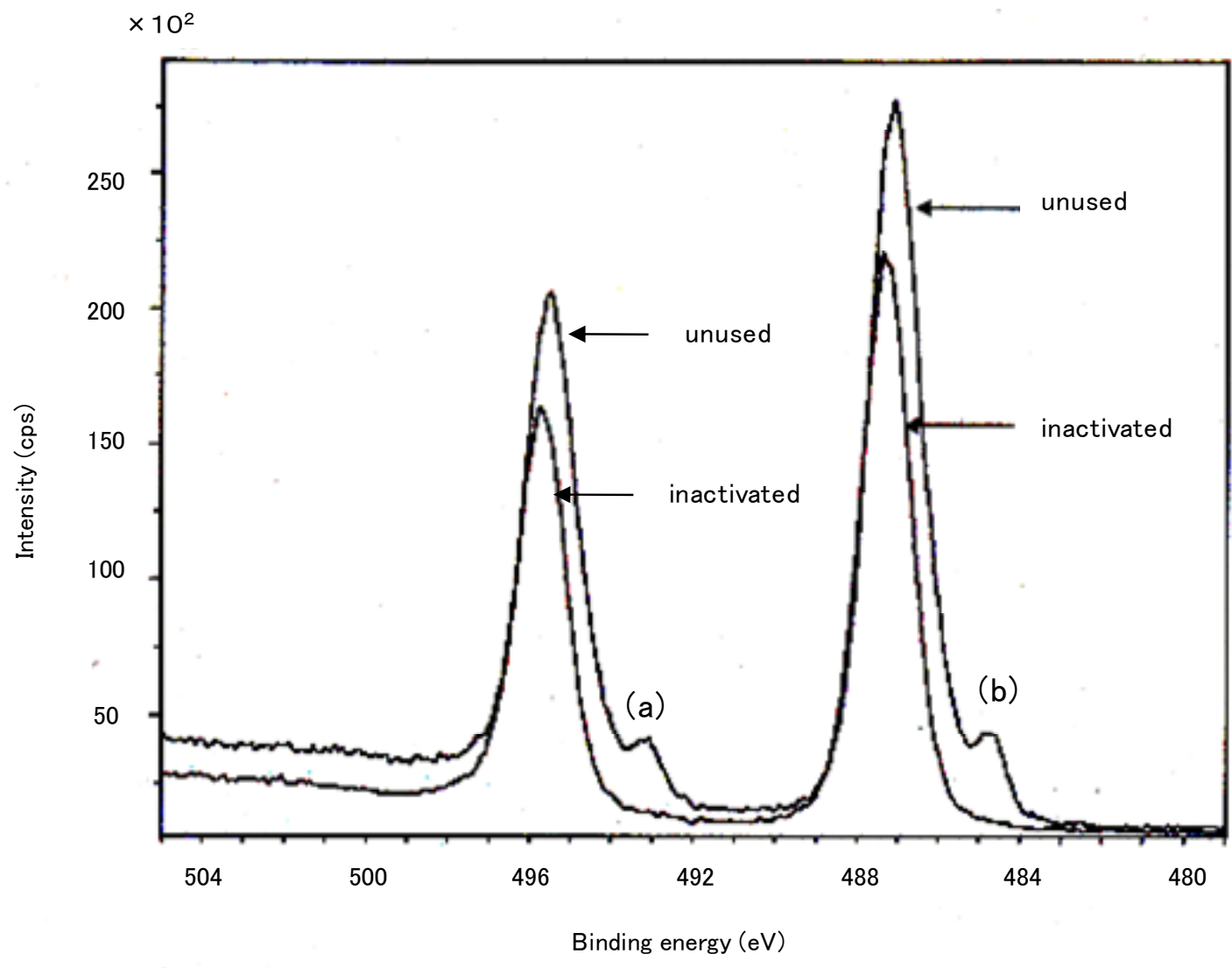

Fig. 7 - XPS Sn3d spectra of the unused PIP tin ball and the inactivated PIP tin ball. 
Table 3 - XPS quantitative results.

\begin{tabular}{lccccc}
\hline & Peak & $\begin{array}{c}\text { Position } \\
{[\mathrm{eV}]}\end{array}$ & $\begin{array}{c}\text { Raw Area } \\
{[\mathrm{CPS}]}\end{array}$ & $\begin{array}{c}\text { Relative } \\
\text { Sensitivity } \\
\text { factor }\end{array}$ & $\begin{array}{c}\text { Atomic } \\
\text { ratio to } \\
\text { total Sn }\end{array}$ \\
\hline Unused PIP tin ball & $\mathrm{O} 1 \mathrm{~s}$ & 531.6 & 20100.0 & 0.780 & 2.6 \\
& $\mathrm{Sn3d}$ & 487.1 & 47164.6 & 4.725 & 1 \\
& $\mathrm{C} 1 \mathrm{~s}$ & 285.0 & 3922.0 & 0.278 & 1.40 \\
& & & & & 3.48 \\
& $\mathrm{O} 1 \mathrm{~s}$ & 531.8 & 18823.1 & 0.780 & 1 \\
& $\mathrm{Sn3d}$ & 487.4 & 32895.2 & 4.725 & 2.63 \\
\hline
\end{tabular}

FT-IR spectra of the precipitate and citric acid monohydrate were obtained and compared with those reported by Tselesh (2008) for $\mathrm{Sn}(\mathrm{II})$-citrate chelate, $\mathrm{SnO}_{2} \cdot \mathrm{nH}_{2} \mathrm{O}$ and $\mathrm{Sn}(\mathrm{OH})_{2}$ as shown in Table 4. Bands at $1390 \mathrm{~cm}^{-1}$ which were attributed to carboxylate $\mathrm{COO}^{-}$were found in the spectra of the precipitate, citric acid monohydrate and $\mathrm{Sn}(\mathrm{II})$-citrate. Bands at $1723 \mathrm{~cm}^{-1}$ and $1228 \mathrm{~cm}^{-1}$ in the spectra of citric acid monohydrate which were attributed to stretching of the $\mathrm{C}=\mathrm{O}$ double bond and of the C-O single bond in carboxylic acid, respectively (Silverstain et al., 1964), were not found in the spectra of the precipitate and Sn(II)-citrate. This indicates that the carboxylic group in the precipitate or $\mathrm{Sn}$ (II)-citrate may be chelated. As $\mathrm{Sn}$ (II) forms a stable complex with citrate (Almedia and Gianneti, 2001; Tselesh, 2008), it is assumed that dissolved Sn (II) from PIP tin balls also forms a complex with citrate. A set of absorption at 2921 and $2851 \mathrm{~cm}^{-1}$, assignable to $v(\mathrm{CH})$ vibration of $\mathrm{CH}_{2}$ groups of citrate ions (Tselesh, 2008), was exhibited in precipitates, while the absorptions were not found in citric acid monohydrate. The absorption bands at $1136 \mathrm{~cm}^{-1}$ in the spectra of the precipitate and $\mathrm{Sn}$ (II)-citrate, and $1158 \mathrm{~cm}^{-1}$ in the spectrum of citric acid monohydrate corresponded to the bending vibrations of $\delta-(\mathrm{OH})$ of $\mathrm{C}-\mathrm{OH}$ groups. The peak at $1245 \mathrm{~cm}^{-1}$ of the spectrum of the precipitate attributed to terminal $\mathrm{Sn}-\mathrm{OH}$ stretching was also found in $\mathrm{Sn}(\mathrm{II})$-citrate, $\mathrm{SnO}_{2} \cdot \mathrm{nH}_{2} \mathrm{O}$ and $\mathrm{Sn}(\mathrm{OH})_{2}$. The bending vibration of $\mathrm{O}-\mathrm{Sn}$ at 659 and $549 \mathrm{~cm}^{-1}$ in the spectrum of the precipitate was found for $\mathrm{Sn}(\mathrm{II})$-citrate, $\mathrm{SnO}_{2} \cdot \mathrm{nH}_{2} \mathrm{O}$ and $\mathrm{Sn}(\mathrm{OH})_{2}$. These results indicated the possibility that tin-citrate complex was included in precipitates. Additionally, it is assumed that the tin-citrate complex became poorly soluble by combining tin oxide and/or tin hydroxide species.

It has been reported that metallic tin is oxidized to soluble $\mathrm{Sn}$ (II ) species in citric acid solution and a $\mathrm{Sn}($ II )-citrate complex is formed. This complex is adsorbed on the tin surface. The adsorbed $\mathrm{Sn}$ ( II )-citrate is oxidized and forms a more stable $\mathrm{SnO}_{2}$ film on the tin surface (Almedia and Giannetti, 2001; Abdel Rehim et al., 2003). XPS analysis showed that metallic tin, $\operatorname{Sn}(0)$ on the surface of the unused PIP tin balls, was not present on the surface of the inactivated balls. The analysis also indicated the increase in the ratio of $\operatorname{Sn}(\mathrm{IV})$ species in inactivated PIP tin balls. It is assumed that $\operatorname{Sn}(0)$ on the surface of the balls was converted to $\mathrm{Sn}(\mathrm{II})$ by adsorption of citrate ion and then formed a soluble $\mathrm{Sn}$ (II)-citrate complex and that the dissolved $\mathrm{Sn}$ (II)-citrate was adsorbed on the surface of the balls and then oxidized to form a thick film of $\mathrm{SnO}_{2}$ and/or $\mathrm{Sn}(\mathrm{OH})_{4}$ by incorporating $\mathrm{Sn}(\mathrm{II})$-citrate complex. The thick film covered the 
metallic tin portion on the surface of PIP tin balls, resulting in its inactivation. As tin dissolves only slightly in acids free from air (Jafarian et al., 2008), the film formation from dissolved tin species was not so vigorously observed under anaerobic condition, not resulting to inactivation.

Table 4 - FT-IR bands assigned to the spectra of precipitates and reference values of Sn(II)-citrate chelate, $\mathrm{SnO}_{2} \cdot \mathrm{nH}_{2} \mathrm{O}$ and $\mathrm{Sn}(\mathrm{OH})_{2}$.

FT-IR band position $\left(\mathrm{cm}^{-1}\right)$

\begin{tabular}{|c|c|c|c|c|c|}
\hline \multirow[b]{2}{*}{ Assignment } & \multicolumn{3}{|c|}{ Tselesh (2008) } & \multicolumn{2}{|c|}{ This work } \\
\hline & $\begin{array}{c}\text { Sn( II )-citrate } \\
(54.3 \% \mathrm{Sn})\end{array}$ & $\mathrm{SnO}_{2} \cdot \mathrm{nH}_{2} \mathrm{O}$ & $\mathrm{Sn}(\mathrm{OH})_{2}$ & Precipitates & $\begin{array}{c}\text { Citric acid } \\
\text { monohydrate }\end{array}$ \\
\hline$v \mathrm{OH}$ & 3593 & & & 3501 & 3500 \\
\hline$v \mathrm{HOH}$ & $3470-3370$ & $3550-3200$ & $3390-3240$ & 3398 & 3417 \\
\hline$v \mathrm{C}=\mathrm{O}$ & & & & & 1723 \\
\hline$v \mathrm{C}-\mathrm{O}$ & & & & & 1228 \\
\hline$v \mathrm{CH}\left(\mathrm{CH}_{2}\right)$ & 2912,2853 & & & 2921,2851 & \\
\hline$v_{\mathrm{as}} \mathrm{COO}^{-}$ & 1545 & & & 1623 & 1619 \\
\hline$v_{\mathrm{s}} \mathrm{COO}^{-}$ & 1390 & & & 1384.7 & 1395 \\
\hline$\delta \mathrm{C}-\mathrm{OH}$ & 1136 & & & 1136 & 1158 \\
\hline $\begin{array}{l}\delta \mathrm{Sn}-\mathrm{OH} \\
\text { terminal }\end{array}$ & 1247 & 1245 & 1248 & 1245 & \\
\hline$\delta \mathrm{Sn}-\mathrm{O}$ & 672,573 & 658,533 & 546 & 659,549 & \\
\hline
\end{tabular}

\section{Reaction mechanism in the presence of citric acid}

The decolorization of four azo dyes was investigated in the presence and absence of citrate. It is reported that the order of the decolorization rate in microbial reduction was Acid red 27, Orange II, and Acid yellow 23, in which the microbial azo reduction occurs sequentially as a function of the substrate reduction potential (Bragger et al., 1997; Semdé et al., 1998). To investigate the correlation in PIP tin balls, three azo dyes were selected. Correlation between the reduction potentials of these three dyes and these decolorization ratios was not found in PIP tin balls (Table 1). We also used Reactive black 5 which belongs to a class of compounds known as reactive azo, which are abundantly used in textile industries for dyeing (Işik and Sponza, 2004). The decolorization ratio of Orange II was the highest among these dyes in the presence and absence of citrate. In Acid red 27 and Acid yellow 23, dramatic enhancement of ratios 
was observed in the presence of citrate. Orange II and Reactive black 5 showed obvious decolorization even by hydrochloric acid. Langmuir-Hinshelwood model was applied in order to study the adsorption of dye on the surface of PIP tin balls to calculate the equilibrium constants. The reaction rate of surface processes could be described by the Langmuir-Hinshelwood equation where rate is proportional to the surface coverage of reactive sites. The equilibrium constants were determined by fitting the experimental data under static condition to the following Langmuir-Hinshelwood equation:

$$
1 / \mathrm{v}_{\mathrm{o}}=1 / \mathrm{k}_{\mathrm{app}}+1 /\left(\mathrm{k}_{\mathrm{app}} \mathrm{K}_{\mathrm{m}}\left[\mathrm{C}_{\mathrm{o}}\right]\right)
$$

Where $\mathrm{v}_{\mathrm{o}}[\mathrm{mM} / \mathrm{min}], \mathrm{k}_{\mathrm{app}}[\mathrm{mM} / \mathrm{min}], \mathrm{K}_{\mathrm{m}}\left[\mathrm{mM}^{-1}\right]$, and $\mathrm{C}_{\mathrm{o}}[\mathrm{mM}]$ are initial reaction rate, apparent reaction rate constant, adsorption equilibrium constant, and initial dye concentration in the decolorization reaction, respectively. A linear expression can be obtained by plotting the reciprocal initial rate against the reciprocal initial concentration. The kinetic parameters which were estimated from equation (4) are shown in Table 5. The adsorption equilibrium constants of Acid yellow 23 and Acid red 27 in the case with hydrochloric acid could not be determined because the initial reaction rates were considerably small. The adsorption equilibrium constants of Reactive black 5 and Orange II were of smaller value in the case including citrate. This would be because the adsorption of azo dyes was disturbed by citrate. This disturbance would be responsible for the adsorption of citrate on the surface of PIP tin ball. The difference of adsorption equilibrium constants between the two acids was considerably large in Orange II. Apparent reaction rate constant reflects the limiting rate of the reaction at maximum coverage of the adsorption site. Apparent reaction rate constant of Reactive black 5 was larger when citrate was included, though the decolorization ratio was smaller with citrate as shown in Table 1. These results indicated that the reactive site was considerably reduced in the presence of citrate leading to the inhibition of decolorization reaction in the case of Reactive black 5.

Table 5 - Langmuir-Hinshelwood kinetic parameters. (The $\mathrm{pH}$ was adjusted to 3 using citric acid or hydrochloric acid. PIP tin ball $: 8 \mathrm{~g}$; reaction solution volume : $2.2 \mathrm{~mL}$ )

\begin{tabular}{ccccc}
\hline & \multicolumn{2}{c}{ With citrate } & \multicolumn{2}{c}{ With hydrochloric acid } \\
\cline { 2 - 5 } & $\mathrm{k}_{\text {app }}[\mathrm{mM} / \mathrm{min}]$ & $\mathrm{K}_{\mathrm{m}}\left[\mathrm{mM}^{-1}\right]$ & $\mathrm{k}_{\text {app }}[\mathrm{mM} / \mathrm{min}]$ & $\mathrm{K}_{\mathrm{m}}\left[\mathrm{mM}^{-1}\right]$ \\
\hline Acid yellow 23 & 0.09 & 0.74 & \multicolumn{3}{c}{ none } \\
Acid red 27 & 0.36 & 0.26 & \multicolumn{3}{c}{ none } \\
Reactive black 5 & 0.04 & 1.38 & 0.02 & 2.12 \\
Orange II & 0.52 & 0.25 & 0.03 & 4.20 \\
\hline
\end{tabular}

The decolorization ratios of Orange II were investigated at various citric acid concentrations (Fig. 3). In increasing concentrations from $2.5 \mathrm{mM}$ to $5 \mathrm{mM}$, the dramatic enhancement of decolorization ratios was observed. However, the enhancement was not observed above $7.5 \mathrm{mM}$, while the solution $\mathrm{pH}$ was gradually decreased in increasing citric acid concentrations. On the contrary, the decolorization ratios were considerably influenced by solution $\mathrm{pH}$ in the case of hydrochloric acid, in which higher decolorization ratio was obtained as solution $\mathrm{pH}$ was decreased (data not shown). In the case of citric acid, the adsorption of citrate on PIP tin balls would be significant for decolorization reaction rather than the effect of $\mathrm{pH}$. 
Difference of kinetics between citric acid and hydrochloric acid was assumed to originate from the difference of surface potential of PIP tin balls. It is indicated that the oxidation process of metallic tin on the surface of PIP tin balls plays an important role in the decolorization reaction. We measured the open circuit potentials of the oxidation reaction (5) of metallic tin both in $5 \mathrm{mM}$ citric acid and in $5 \mathrm{mM}$ hydrochloric acid and the values were $-270 \mathrm{mV}$ and $-173 \mathrm{mV}$ respectively, with reference to the standard hydrogen electrode (SHE).

$$
\mathrm{Sn}(0) \rightarrow \mathrm{Sn}(\mathrm{II})+2 \mathrm{e}^{-}
$$

The large difference of open circuit potential would be due to the adsoption of citrate at active $\operatorname{Sn}(0)$ sites on the PIP tin balls followed by the oxidation of $\operatorname{Sn}(0)$ to $\operatorname{Sn}($ II ). The oxidation reaction would be thermodynamically favored by the stabilization of Sn( II )-citrate complex (Survila et al., 2000). The acceleration of oxidation reaction generates higher negative potential, leading to improve the reduction of azo dyes. The driving force for a redox reaction is expected closely to relate to the difference between the redox potential of oxidant and reductant. The reduction potential of Reactive black 5 is negatively higher compared with other dyes (Zille et al., 2004). Therefore, sufficient driving force of a reducing reaction of this dye could not generate from the difference of the redox potential between the dye and PIP tin balls even in the presence of citrate. This would also be the reason why the enhancement of citrate was not observed in this dye, together with the disturbance of adsorption by citrate.

\section{CONCLUSION}

It has been demonstrated that obvious decolorization of azo dyes could be obtained in the presence of citric acid under static condition and at room temperature. Such mild condition is costly effective because it does not demand any operating energy. We also performed repeated decolorization of Orange II under stirring condition, where inactivation was observed because of film formation on the surface under ambient condition, but greater than $96 \%$ decolorization ratio of Orange II was obtained throughout five repeated cycles under a nitrogen atmosphere. Thus, after conversion of Orange II by PIP tin balls to ABS and 1A2N, biological methods can be used for further treatment, because the two products are more biodegradable than Orange II. However, release of the dissolved tin in the environment is an unwanted problem. Dissolved $\mathrm{Sn}$ (II) species are easy to precipitate by forming insoluble tin hydroxide at higher $\mathrm{pH}$. Thus, the recovery of dissolved tin would be possible by controlling the $\mathrm{pH}$. Recycling of recovered tin is needed to better utilize PIP tin balls for practical applications in future work.

\section{REFERENCES}

Abdel Rehim S.S., Sayyah S.M. and El Deeb M.M. (2003). Corrosion of tin in citric acid solution and the effect of some inorganic anions. Mat. Chem. Phys., 80, 696-703.

Almeida C.M.V.B. and Giannetti B.F. (2001). Protective film growth on tin in perchlorate and citric acid electrolytes. Mat. Chem. Phys., 69, 261-266.

Alquerque M.G.E., Lopes A.T., Serralheiro M.L., Novais J.M. and Pinheiro H.M. (2005). 
Biological sulphate reduction and redox mediator effects on azo dye decolorization in anaerobic-aerobic sequencing batch reactors. Enz. Microb. Technol., 36, 790-799.

Bragger J.L., Lloyd A.W., Soozandehfar S.H., Bloomfield S.F., Marriott C. and Martin G.P. (1997). Investigation into the azo reducing activity of a common colonic microorganism. Int. J. Pharma., 157, 61-71.

Cao J., Wei L., Huang Q., Wange L. and Han S. (1999). Reducing degradation of azo dye by zero-valent iron in aqueous solution. Chemosphere, 38, 565-571.

Cheng S.-F. and Wu S.-C. (2000). The enhancement methods for the degradation of TCE by zero-valent iron. Chemosphere, 41, 1263-1270.

Delée W., O’Neill C., Hawkes F.R. and Pinheiro H.M. (1998). Anaerobic treatment of textiles effluents: a Review. J. Chem. Technol. Biotechnol., 73, 323-335.

Işik M. and Sponza D.T. (2004). A batch kinetic study on decolorization and inhibition Reactive black 5 and Direct brown 2 in an anaerobic mixed culture. Chemosphere, 55, 119-128.

Jafarian M., Gobal F., Danaee I., Biabani R. and Mahjani M.G. (2008). Electrochemical studies of the pitting corrosion of tin in citric acid solution containing $\mathrm{Cl}^{-}$. Elecrochim. Acta, 53, 4528-4536.

López C., Moreria M.T., Feijoo G. and Lema J.M. (2004). Dye decolorization by manganese peroxidase in an enzymatic membrane bioreactor. Biotechnol. Prog., 20, 74-81.

Mielgo I., Moreria M.T., Feijoo G. and Lema J.M. (2001). A packed-bed fungal bioreactor for the continuous decolourisation of azo-dyes(Orange II ). J. Biotechnol., 89, 99-106.

Mu Y., Yu H.Q., Zhang S.J. and Zheng J.-C. (2004). Kinetics of reductive degradation of Orange II in aqueous solution by zero-valent iron. J. Chem. Technol. Biotechnol., 79, 1429-1431.

Nam S. and Tratnyek P.G. (2000). Reduction of azo dyes with zero-valent iron. Wat. Res., 34,1837-1845.

Semdé R., Pierre D., Geuskens G., Devleeshouwer M. and Moës A.J. (1998). Study of some important factors involved in azo derivative reduction by Clostridium perfringens. Int. J. Pharma., 161, 45-50.

Silverstein R.M., Bassler G.C. and Morrill T.C. (1964). Spectrometric identification of organic compounds. Wiley, New York.

Stolz A. (2001). Basic and applied aspects in the microbial degradation of azo dyes. Appl Microbiol Biotechnol., 56, 69-80.

Survila A., Mockus Z. and Kanapeckaite S. (2000). Kineticks of Sn and Co codeposition in citrate solutions. Electrochim. Acta, 46, 571-577.

Tselesh A.S. (2008). Anodic behavior of tin in citrate solutions: The IR and XPS study on the composition of the passive layer. Thin Solid Films, 516, 6253-6260.

Van der Zee F.P. and Villaverde S. (2005). Combined anaerobic-aerobic treatment of azo dyes-A short review of bioreactor studies. Wat. Res., 39. 1423-1440.

Willemen H., Van De Vondels D.F. and Van Kelen G.P. (1979). An ESCA study of tin compounds. Inorg. Chim. Acta, 34, 175-179.

Zille A., Ramalho P., Tzanov T., Millward R., Aires V., Helena M., Ramalho M.T., Gübitz G.M. and Cavaco-Paulo A. (2004). Predicting dye biodegradation from redox potentials. Biotechnol. Prog., 20, 1588-1592. 